\title{
The Plural Is Semantically Unmarked
}

\author{
Uli Sauerland, Jan Anderssen, and Kazuko Yatsushiro
}

In the first century b.c., Marcus Terentius Varro used the terms singularis and multitudinis in his grammar of Latin, De Lingua Latina, to refer to two classes of morphological marking (cf. Taylor 1996). Soon after Varro's writing, the term pluralis replaced multitudinis (e.g. in Marcus Fabius Quintilian's Institutio oratoria in the first century A.D.) while the term singularis caught on. Varro's choice of terminology seems to have been inspired by a semantic intuition: Singularis literally means 'alone' and presumably was taken to mean that the cardinality of the intended referent of a noun is equal to one. Multitudinis, on the other hand, derives from multitudo ('multitude/great number'). ${ }^{1}$ Pluralis, which replaced Varro's term, derives from plus ('more'). This choice of terminology suggests that multitudinis/pluralis forms entail that the cardinality of the intended referent is greater than one. Varro's term singular and the term plural have come to be widely used in the linguistic literature as many languages display a similar distinction as Latin does. Moreover, Varro's semantic intuition is widely accepted in current semantic work. For example, a fairly recent work on the semantics of plurality simply states: [Plurality] just means 'more than one' (Lasersohn 1995, ix).

There are, however, several cases where the plural does not seem to imply cardinality greater than one. Consider the a. examples in (1) through (4), and compare them to the b. examples where two or more (or zwei ('two') in the German (4b)) is added to the plural noun. ${ }^{2}$

(1) a. You're welcome to bring your children.

b. You're welcome to bring your two or more children.

(2) a. Every boy should invite his sisters.

b. Every boy should invite his two or more sisters.

(3) a. No chairs are available.

b. Two or more chairs aren't available

(4) a. Könnten Sie bitte etwas rücken.

Could pro.3PL please a little move

'Could you please move over.' 
b. Könnten Sie zwei bitte etwas rücken. Could pro.3PL two please a little move 'Could you two please move over.'

Each of these pairs shows that the plural does not mean the same as explicitly adding two or more: In (1), the plural in (a) can be used if the speaker is unsure about the number of children of the addressee, but to use the (b)-sentence the speaker has to be sure that the addressee have two or more children. In (2), the plural in (a) only requires that some of the boys have more than one sister, while two or more in (b) requires that all have more than one. In (3), the plural in (a) excludes even the availability of one chair, while two or more as in (b) actually implicates the availability of one chair. Finally, (4a) shows that the plural pronoun sie in German can be used to address a single individual, but this is impossible in (4b) where zwei ('two') is added. The phenomena illustrated in (1) through (4) are problems for Varro's semantics of the plural.

In this paper, we call Varro's theory and its modern descendants the Strong Theory of the plural. We argue instead for the Weak Theory, where the meaning of the plural is strictly weaker than that of the singular. In the weak theory, pragmatic principles block the use of the plural in cases where the singular is appropriate, rather than its inherent semantic content. We are not the first to propose that Varro's strong theory be replaced by some version of the weak theory. However, previous writers focus on the problem the strong theory has with the determiner no illustrated by (3) (Hoeksema 1983; van Eijck 1983; Schwarzschild 1996; Beck and Sauerland 2000). A fellow Roman, Chierchia (1998), defends Varro's strong theory against this particular criticism. Namely, Chierchia proposes to simply change the semantics of no in such a way that the plural no chairs (and also the singular no chair) are equivalent to no chair or chairs. In this paper, however, we show a set of other arguments for the weak theory from several different kinds of evidence. In the process, we also spell out the weak theory in more detail than what previous research has accomplished.

Our arguments also show how several different types of evidence can be brought to bear on the same linguistic issue. In particular, we present evidence from adult competence in sections 2,3 , and 4 , evidence from child performance in 5, and evidence from adult performance in 6 . In the initial section 1 that follows, though, we spell out the two accounts that we compare. 


\section{Two Theories of the Plural}

In this section, we spell out the two accounts of number we compare; the strong and weak theory. We will then compare these two accounts in the following sections.

For concreteness, we adopt the proposal argued for in Sauerland (2003) that agreement features express presuppositions and are interpreted in a separate lexical head, $\phi$, that takes DP as its complement. Sauerland (2003) shows that number marking on the common noun itself cannot be assigned an interpretation, and argues that number marking on nouns as well as on determiners, adjectives, and verbs is the reflex of syntactic agreement with number marking in $\phi$. In this theory, the interpretation of feature singular is the purely presuppositional requirement that its complement refer to a single atomic entity.

$$
\begin{aligned}
& [\mathrm{SING}]](x) \text { is defined only if } \# x=1 \\
& {[[\operatorname{SING}](x)=x \text { wherever it is defined }}
\end{aligned}
$$

We assume here that entities are conceptualized in a way that can be captured by the mereological notions atom and part of (we leave mass nouns for future research). For example, John is conceptualized as a single atomic entity, while John and Bill are conceptualized as a non-atomic entity that has the two atomic parts that correspond to John and Bill and no other parts. We assume that the operator \# gives the number of atomic parts of an entity.

The semantics of the plural is the only place in which the strong and weak theory differ. The strong theory amounts to the semantics in (6).

$$
\begin{aligned}
& {[\text { PLUR }](x) \text { is defined only if } \# x>1} \\
& {[\text { PLUR }](x)=x \text { wherever it is defined }}
\end{aligned}
$$

The weak theory, on the other hand, assume that the plural has no presupposition. The lexical entry in (7) captures this proposal.

$$
\begin{aligned}
& {[\text { PLUR }](x) \text { is always defined }} \\
& {[\text { PLUR }](x)=x \text { wherever it is defined }}
\end{aligned}
$$

On the weak theory the distribution of the plural feature is therefore not restricted by an inherent presupposition, but by pragmatics. In particular, Heim (1991) argues for the principle Maximize Presupposition which can be directly applied in this case. Heim's principle requires that, of two alternative morphemes, the one that has a stronger presupposition must be used whenever its presupposition is satisfied. This principle does not apply to singular and plural when the strong theory of the plural is adopted because the presuppositions are mutually exclusive. But on the weak theory of the plural, 
the principle applies since the presupposition of the plural is strictly weaker than that of the singular: Any entity $x$ that satisfies the presupposition of SING also satisfies the vacuous presupposition of PLUR. We derive the following corollary of maximize presupposition for number: Use the plural only if the singular is blocked. One consideration that can block the singular is, of course, if the referent is non-singular.

Consider the examples in (8) for an illustration of both the weak and the strong theory.

(8) a. The boy, Kai, smiles.

b. The boys, Kai and Hannes, smile.

On the versions we are considering both accounts assume that the syntactic structure of the subject in (8) is the following, with the appropriate number marking in $\phi$ :

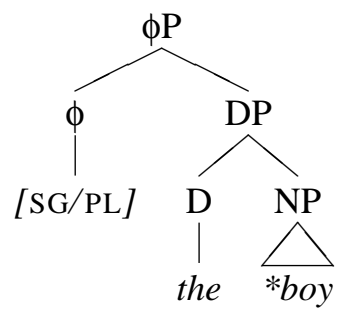

Following Sauerland (2003), we assume that the NP *boy in (8) is the number-neutral predicate that is true of any entity that has at least one boy as its part and exclusively boys as its parts. The definite determiner the picks out the maximal entity satisfying its complement. If only Kai is salient, as in (8a), the DP therefore refers to Kai. Since Kai is conceptualized as an atom, the presupposition of the singular is satisfied, and singular marking is therefore possible in this situation. Furthermore, plural marking is predicted to be semantically anomalous. On the strong theory, PLUR would presuppose that Kai contains more than one atom, which is not the case. On the weak theory, on the other hand, the presupposition of PLUR is satisfied, but PLUR can only be used if presupposition of the singular is not also satisfied. However, the presupposition of SING is satisfied in (8a) and therefore use of PLUR is anomalous. In (8b), on the other hand, two boys are salient and therefore the DP-constituent in the structure above refers to the plurality that has these two boys as its atomic parts. Since the plurality of Kai and Hannes itself is not an atom, the presupposition of SING is not satisfied in this case. The plural, however, can occur in $\phi$ : On the strong theory, this follows because the pre- 
supposition of PLUR is satisfied, and on the weak theory it follows from the fact that SING is blocked.

\section{Mixed Reference}

Consider the following scenario: You are inviting an old friend who you have not seen in years. You heard that he has a family now, but you have no idea how many children he has. In this scenario, you could use the plural as in $(9 \mathrm{a})$, but the singular in (9b) would be odd. You could also use the disjunction in $(9 \mathrm{c})$, but this seems less natural than $(9 \mathrm{a}){ }^{3}$

(9) a. You are welcome to bring your children.

b. \#You are welcome to bring your child.

c. You are welcome to bring your child or your children.

In this scenario, if your friend happened to have only one child, he would naturally assume that he may bring his child.

Consider also the difference between (10a) and (10b). If the plural leads to a presupposition that you have more than one child, only the conditional in (10b) should block the projection of this presupposition. But instead, (10a) seems to not presuppose that the addressee have a certain number of children. (10b), on the other hand, presupposes that the addressee have at least one child. On the weak theory, the facts in (10) follow from the well-known generalization that a conditional "if $p, q$ " presupposes whatever $q$ presupposes except for those presuppositions of $q$ entailed by $p$.

(10) a. You may bring your children if you have any.

b. You may bring your children if you have more than one.

The examples in (11) can be used to make a similar point. Consider the following scenario: The boys in the football club want to have a party. They wonder though how to get girls to come to their party. The coach knows exactly how many sisters each boy has. Every boy has at least one sister, and in particular, Bill has exactly one sister, while Tom has three. The coach could then use (11a), but not (11b), to suggest that all the sisters be invited.

(11) a. Every boy should invite his sisters to the party.

b. \#Every boy should invite his sister to the party.

In (11), the definite description contains a variable (the pronoun his) and depending on the value assigned to this pronoun the definite refers to different entities. The generalization is that the plural must be used if the definite refers to an entity that contains more than one atom for at least some of the assignments considered for the variable. Hence, (11b) is odd unless every 
boy has exactly one sister. We assume that the examples in (9) are analyzed in a similar way by assuming that the DP your children contains a world variable that ranges over the worlds in the common ground. As long as the addressee has more than one child in some of the worlds, the plural must be used. The tests in (9) and (11) are similar to one Greenberg (1966, p. 30) presents and attributes to Arab grammarians, who introduced the term taghlī $b$ ('dominance') for it. The argument in this case is that only the unmarked form of a pair of two features can be used to refer to a plurality of individuals only some of which have the marked property. One of Greenberg's examples is the difference between the plural of father and mother in Spanish: los padres ('the fathers') can also mean 'the parents', while las madres ('the mothers') only means 'the mothers'. The difference follows from the assumption that the masculine feature is less marked than the feminine feature. While the dominance test cannot be conducted for number marking using just a single DP because the DP would be plural for independent reasons, the clausal examples in (9) and (11) with a variable in the DP are closely related.

The difference between singular and plural marking in (9) and (11) follows directly from the weak theory of number marking we advocate. Consider first (11). We assume that universal quantifiers project presuppositions from their scope universally as in (12).

$$
\begin{aligned}
& \llbracket \text { every }](P)(Q) \text { is defined only if } \forall x: P(x)=1 \rightarrow x \in \operatorname{domain}(Q) \text { and } \\
& \exists x: P(x)=1 ; \\
& \text { [every }](P)(Q)=1 \text { if and only if } \forall x: P(x)=1 \rightarrow Q(x)=1
\end{aligned}
$$

From (12), it follows that the inherent presupposition of the singular projects the presupposition: Every boy has exactly one sister. The plural, however, can be used whenever the presupposition of the singular is not satisfied (and in addition the existence presupposition of the definite that every boy has at least one sister is satisfied). This predicts that the plural is felicitous whenever at least one boy has more than one sister. Note that the strong semantics of the plural would predict a stronger presupposition for the plural; namely, that each boy has two or more sisters. As we have argued, only the prediction of the weak theory is correct. The account carries over to (9) if we assume that for a sentence to be felicitous in a context, it must be defined in all worlds of the common ground of that context.

\section{Plural Pronouns with Singular Reference}

In many cases, plural pronouns can be used to refer to single individuals. One cross-linguistically very widespread case is the pluralis reverentiae. Consider 
the German example in (13), which literally says "Could they please move a little?", using a third person plural pronoun. (13), however, is the normal way a German adult would address another adult he does not know, e.g. the person sitting next to him on the plane.

$$
\begin{aligned}
& \text { Könnten sie bitte etwas rücken? } \\
& \text { Could pro.3PL please a little move sideways } \\
& \text { 'Could you please move a little?' }
\end{aligned}
$$

If sie is replaced with the second person singular pronoun $d u$ as in (14), the sentence would only be used to either address a child or another adult that the speaker is friendly with.

$$
\begin{aligned}
& \text { Könntest du bitte etwas rücken? } \\
& \text { Could pro.2sG please a little move sideways }
\end{aligned}
$$

This phenomenon is cross-linguistically very common. A typological study by Head (1978) lists 84 languages that use a shift of number in second person pronouns from singular to plural to show degrees of respect or social distance. ${ }^{4}$ German is slightly unusual in so far as it uses the third person rather than the second person plural form. More frequently, the second person plural pronoun is used, which is for example attested in Elizabethan English. Consider the two examples in (15) from Shakespeare's King Lear (4.6, 1.7-8 and 1.10). The speaker here switches from the second person singular thou to the more polite second person plural you as he forms the opinion that addressee is of equal social rank.

$$
\begin{aligned}
& \text { a. Thou speak'st in better phrase and matter than thou didst } \\
& \text { b. Methinks you're better spoken. }
\end{aligned}
$$

Modern English has lost the singular/plural distinction in the second person pronouns and with it the use of this distinction to express respect. However, the phenomenon of Singular They in Modern English, which is illustrated by (16) is, we believe, similar. In (16), plural they can be used even it was just one umbrella owned by a single person that was left behind.

\section{(16) Someone left their umbrella.}

Brown and Levinson (1987) develop one idea to explain the possibility of using a plural pronouns with singular reference based on the strong theory of the plural. Their assumption is, if we understand it correctly, that the speaker pretends to be addressing a group of people even when he is just addressing a single person. Addressing a group is less direct than singling out the addressee with a singular pronoun, and therefore considered more polite. This indirect address is conventionalized in those languages that allow the 
use of plural pronouns for the polite address of a single person. However, the proposal of Brown and Levinson (1987) has a number of problems. For one, it does not extend to singular they in (16). Furthermore, (17) presents a serious problem for the proposal: Imagine a scenario where a surgeon addresses a patient, Ms. Meier, whose nose needs to be operated on. It would be very natural to use the plural sie to address her. But, if the surgeon was hereby addressing an imagined group of people, this group of people should have more than one nose. Therefore, Brown and Levinson's proposal predicts that (17) with the plural marking on Nase should be used by the surgeon. Yet, (17) is distinctly odd unless Ms. Meier actually has more than one nose. ${ }^{5}$ As far as we can see, (17) is fatal for Brown and Levinson's proposal.

(17) \#Frau Meier, ihre Nasen müssen operiert werden. Ms. Meier, pro.3PL nose-PL must-PL operated be.

'Ms. Meier, you must receive surgery on your noses.'

In sum, we do not know of any proposal based on the strong theory of the plural that would cover all uses of plural pronouns with singular reference. One idea that was occasionally brought up to us after presentations is that the use of the plural is a metaphor for power in the polite pronouns. While it might be worthwhile to try to make this idea more precise, as far as we can see, the fact that also a pluralis modestiae exists is going to create problems for this idea. This label has been given for the use of the first person plural instead of the singular in certain contexts. For example, writers in the natural sciences are exhorted to use we instead of $I$ to refer to themselves even when a paper has only a single author. In these cases, the plural is not intended to stress the authority of the author, but rather to avoid the pronoun $I$ for stylistic reasons. On the weak theory, on the other hand, it is expected that in case $I$ is blocked the plural form can be used. In sum, we believe that the different uses of plural pronouns with singular reference constitute a significant problem for the strong theory of the plural.

On the weak theory, on the other hand, singular reference of plural pronouns does not create a semantic problem at all since the semantics of the plural does not exclude singular reference. If the singular cannot be used, it follows that the plural can occur despite singular reference. The remaining question is why the singular cannot be used. We assume that various stylistic conventions can block the singular pronoun: In the case of singular they, the gender marked singular pronouns he/she/it must be avoided when the gender of the referent is unknown, and therefore the plural form can be used. In the context of pluralis modestiae, $I$ is blocked, and therefore the plural we can 
be employed. Finally, in the pluralis reverentiae cases, the second person singular pronoun is blocked by a convention in certain languages. This accounts for the shift in Elizabethan English from singular thou to plural you. In Modern German, where in addition we observe a shift in person, we assume that third person is semantically vacuous just like the plural, and the politeness convention blocks not just the second person singular $d u$, but also third person singular er/sie/es and second person plural ihr. Therefore, only the third person plural pronoun remains and is used. This line of reasoning receives further support from the observation that in the historical development of German, ihr and er/sie/es have been used with second person singular reference, and that at stages where such uses of ihr and er/sie/es cooccurred with singular uses of sie, sie was always considered the more reverential (Simon 2003).

\section{Indefinites in Downward Entailing Contexts}

In this section, we look at an argument from number marking on indefinites in downward entailing environments. Previous literature has shown, as we mentioned in the introduction, that plural marking on the argument of English determiner no does not exclude singularity. In this section, we consider number marking on indefinites more broadly and then present an analysis within the presuppositional account of number that assumes the weak analysis of the plural.

Consider the examples in (18) where plural marking occurs in the scope of negation.

$$
\begin{aligned}
& \text { a. Kai hasn't found any eggs. } \\
& \text { b. Kai has found no eggs. }
\end{aligned}
$$

Both sentences are judged true only if Kai has not even found a single egg. It seems that generally plural indefinites in a downward entailing environment include reference to a singular: (19a) on the label of a yoghurt bottle says that there is not even a single artificial ingredient in the yoghurt. In (19b), if the conditional was true only if John ate a plurality of apples, there should be at least two less in the basket. But, while the sentence is a tautology with one less, it would be false with two less unless John has a habit of never eating single apples.

(19) a. Without artificial ingredients

b. If John had eaten any apples from the basket, there would be at least one/\#two less in the basket. 
It seems therefore that number marking on indefinites in a downward entailing environment does not affect truth conditions. Outside the scope of negation, however, number marking on indefinites does affect truth conditions. For example, (20a) entails that there is more than one egg still hidden, while (20b) does not. In fact, (20b) has an implicature that only one egg is still hidden.

(20) a. Some eggs are still hidden.

b. Some egg is still hidden.

Furthermore, (21) entails that there is more one than one egg that Kai could not find. Since the indefinite here cannot take scope below negation, though it is c-commanded by it, (21) shows that the semantic scope of negation determines whether number marking has an effect on interpretation.

(21) Kai couldn't find certain/some eggs.

As far as we know, the only attempt to account for this set of facts is a speculative suggestion by Sauerland (2003). Chierchia (1998) suggests that number marking on indefinites is generally not interpreted, but that cannot account for indefinites outside the scope of negation as in (20) and (21). Our account builds on some of the suggestions by Sauerland (2003), but differs from it in the ways noted below.

For the determiner no, we assume that it must be decomposed syntactically into an indefinite and negation (Bech 1955/1957; Jacobs 1980; Penka 2002, and others). We therefore focus on the examples with the indefinites some and any. We assume that the indefinites are analyzed as existential quantifiers of the type of generalized quantifiers.

$$
\text { [ssome/any } \rrbracket(P)(Q)=1 \text { iff. } \exists x: P(x)=1 \wedge Q(x)=1
$$

Consider first indefinites that do not occur in the scope of negation as in (20). We assume that the indefinite must undergo quantifier raising from the position below the number morpheme. For (20), this derives (23) as the LFrepresentation.

(23) [some egg] $\lambda_{x} \operatorname{SING/PLUR}(x)$ is still hidden.

Since SING and PLUR express a presupposition, we need to know at this point how presuppositions project from the scope of an existential and how this interacts with presupposition maximization. For the projection question, we assume what seems to be the most straightforward proposal; namely that there is no projection, but that the presupposition becomes part of the assertion. ${ }^{6}$ This proposal is already implicit in the lexical entry in (22) since we assume that presuppositions are formally captured as truth value gaps, and therefore 
the $P(x)=1$ can only be fulfilled if $x$ satisfies the presuppositions of $P$. The statement of the lexical entry in (24) makes the proposal more explicit.

$$
\begin{aligned}
& {[\text { ssome/any }](P)(Q)=1 \mathrm{iff} .} \\
& \quad \exists x \in \operatorname{domain}(P) \cap \operatorname{domain}(Q): P(x)=1 \wedge Q(x)=1
\end{aligned}
$$

The interpretation assigned to (23) with singular therefore can be paraphrased as: There is an atomic entity that is an egg and is still hidden. For the plural, the weak theory predicts the paraphrase: There is some entity that consists of one or more eggs and is still hidden. In neither case, the interpretation of the entire sentence has a presupposition, and therefore presupposition maximization does not apply straightforwardly. In fact, the two representations are predicted to be equivalent once distributivity is taken into account: The singular entails the plural straightforwardly because we are assuming the weak theory of the plural. But, the reverse entailment also holds since being an egg and being hidden are true of a plurality if and only if they are true of all atomic parts of that plurality. Therefore, this analysis correctly predicts that number marking does not affect truth conditions for occurrences of indefinites in a downward entailing environment as in (18). For indefinites not in the scope of negation as in (23), however, number marking does make a contribution. We propose the generalization in (25):

Maximize presupposition applies to the scope of an existential if this strengthens the entire utterance.

Consider how (25) applies to (23) with plural marking. The scope of the existential is interpreted as a total function since plural does not introduce a presupposition. The alternative with singular, however, is a partial function defined only for atoms. Presupposition maximization applied to the scope of the existential therefore predicts that the domain of the function excludes all atoms. This requires then that there be a plurality of eggs that is still hidden.

After the application of (25), the singular version of (23) has strictly weaker truth conditions than the plural. Therefore, the implicature that no more than one egg is still hidden is predicted. It is interesting to note that presupposition maximization and implicature computation must apply sequentially in this case.

For examples like (18), maximize presupposition applied to the scope of the existential does not lead to a strengthening of the entire utterance because in this case the existential occurs in a downward entailing environment. Since presupposition maximization applied to the scope adds a condition to the scope of the existential, it makes the entire utterance logically weaker when the existential occurs in a downward entailing environment. (25) blocks pre- 
supposition maximization in this case. Therefore our analysis predicts that number marking on existentials in a downward entailing environment is without truth-conditional effect. ${ }^{7}$

\section{Evidence from Child Performance}

The data from adult competence we considered in the previous sections argue that the singular and the plural involve fundamentally different interpretive processes: The lexical entry for the singular inherently presupposes cardinality one. The plural, however, possesses no inherent presupposition. The interpretive effect of the plural arises only from a comparison with the singular regulated by the maxim of maximize presupposition. The comparison process which is involved in the interpretation of the plural is very similar to the the Gricean model of the process that derives scalar implicatures. This similarity is the point of departure of the experimental evidence from child language, we present in this section. Recent work by Noveck (2001), Gualmini et al. (2001) and Papafragou and Musolino (2003) has shown that children acquire scalar implicatures quite late, such that many children at age 5 do not exhibit adult-like behavior in implicature tests. We therefore hypothesized that children of the same age group would not understand plural marking in an adult-like fashion.

The experiment which we report here is inspired by a pilot study of Anne Vainikka, which is reported in de Villiers and Roeper (1991). Unfortunately the original data of this study seem to be lost. According to the brief report of the study children around age 5 answer to questions like (26) with 'yes', while adults would answer ' $n o$ '.

(26) Does a dog have tails?

We conducted an experiment on children's performance on items that contain bare plurals. The subjects were 14 monolingual English speaking children from 3;4 to 5;9. The children were tested at day care centers in Amherst, Massachusetts and Storrs, Connecticut, USA.

In the experiment, each child was asked 13 Yes/No questions. The experimenter held and manipulated a puppet, and pretended that the puppet was asking these questions. The child's task was to help the toy figure by answering 'Yes' or 'No' to the questions. Examples of the test items are shown in (27). The experiment contained 5 test items. The test sentences were all sentences to which we expect adults would answer ' $n o$ '. In fact, the experiment on adult performance we show in the following section shows that adults overwhelmingly answer ' $n o$ ' to such questions. 
a. Does a girl have noses?

b. Does a boy have tongues?

The experiment furthermore contained 8 control items. Examples of control items are in (28). For some control items, the adult response is ' $n o$ ', while for others it is 'yes'.

(28) a. Does a fish have legs?

b. Does a boy have beaks?

c. Does a cat have feet?

The participants were instructed that the toy figure is a space alien who has lots of questions about life on Earth. The participants were asked to help the toy figure by answering its questions. The 13 items were presented in the same order to all participants.

The result of the experiment is shown below. For the test items, the children answered 'yes' to the questions $96 \%$ of the time. Recall that the adultlike performance is to say ' $n o$ ' to these questions. For the control items, on the other hand, the children gave the adult-like responses most of the time. The result is highly significant in an unpaired, two-tailed t-test $(p<.00001)$.

(29) a. Test items: $4 \%$ adult-like (67/70)

b. Control items: $97 \%$ adult-like (3/112)

The result is consistent with our hypothesis that children of this age group do not understand plurality in the way as adults do, and therefore corroborates the weak theory of plurality. Of course, the effect we observe might also be due to other factors. Specifically, we want to consider two alternative explanations: that the children do not perceive plural morphology and that the children treat questions like (27) in the same way as downward entailing environments are treated by adults as discussed in the previous section.

Consider first the hypothesis that the children did not perceive plural morphology, which was word-final /s/ in all of our test items. We attempted to test for children's perception of $/ \mathrm{s} /$ in a independent way in a pilot experiment for six of the 14 participants, but the result did not prove that children perceive /s/. Nevertheless, we think that it is unlikely that children generally are not capable to perceive plural marking in our test items. For one, the absence of any determiner serves as an additional marker of plurality in our test items. Furthermore, for one of the three items in our pilot experiment subjects seemed to be sensitive to the presence of word-final /s/: In this item, children were asked (30a) and shown two pictures: One where Johnny is shown with some boards, and one where Johnny is looking bored, which would have been appropriate for (30b). 5 out of the six children selected the 
correct picture providing some indication that they perceived /s/ in this case.

a. Where can you see Johnnie's boards.

b. Where can you see Johnnie's bored.

The other alternative hypothesis relates to our observation in the previous section that plural and singular are both interpreted as numberless and therefore truth-conditionally equivalent in downward-entailing environments. Whether questions are downward-entailing is unclear as far as we know. Even if we assume that licensing of a negative polarity item (abbreviated NPI in the following) is a sure test for being downward-entailing, questions exhibit an intricate pattern: Work currently in progress by Yael Sharvit and Elena Guerzoni shows that some embedded questions license NPIs, while others do not depending on the embedding verb.

Now consider again the matrix questions in (26) and (27). Here plural morphology on the indefinite does have a truth conditional effect. Otherwise, (26) should be equivalent to the question Does a dog have a tail or tails?, and therefore we would expect it to be answered with 'yes', and an analogous point applies to (27). For the questions in (26) and (27), this does not correspond to our intuitionms and our intuition was corroborated in the processing experiment we report in the following section. This is not the only possible outcome though. Imagine the following scenario. You have just moved into a new office. You have been talking for weeks now about how you really like to look outside from inside your office, and how you hope your new office will have a window. You were not able to find out about this however, up to the day you moved in. In the evening of that day, your friend calls you and asks the question in (31). It would be odd for you to answer (31b) instead of (31a), even when you assume the facts to be just like those under which (30) and (29) were asked, in that your office has only one window, just as a dog has only one tail (cf. Krifka 1989).

(31) Does your office have windows / a window?

a. Yes, (only one though.)

b. \#No, only one.

Number marking does not seem to make a difference in (31), while it appears to matter in (26) and (27). We suggest that the questions in (26) and (31) exemplify two different kinds of questions, and that this difference explains the difference in responses. In the following, we will call questions like (31) true information seeking questions, while we refer to questions like (26) as exam type questions. The difference between the two types of questions is whether the questioner knows the answer to the question or not. 
The distinction we draw between information seeking questions and exam type questions, however, seems to be irrelevant to the interpretation of NPIs. Both types of questions license NPIs. Specifically, (32) shows that an examtype question licenses the NPI ever.

(32) For 50 points: Did Shakespeare ever get married?

From the previous three paragraphs, we have seen that the interpretation of indefinite plurals in questions is subject to several pragmatic factors that we did not control for in our initial acquisition study. Therefore, it is possible that the effect we observed is due to factors other than the process the interpretation of the plural requires, and future work should investigate this possibility. For the time being, however, we conclude that our initial result is predicted by the weak semantics of the plural given the acquisition results on implicatures.

\section{Evidence from Adult Performance}

If something is impossible for children, it might well be hard for adults too. The work we report in this section investigates whether the additional mental processes that are required in the interpretation of the plural can be detected in adult performance. In particular, we expect that comprehending a sentence containing a bare plural requires the comparison process that is assumed by the weak theory. If two is added to the plural, however, the comparison process is no longer necessary for the interpretation of the plural. If the use of mental resources was to correlate with reading times, we expect a reading time difference between the two items.

To test this prediction we conducted a processing experiment. 43 undergraduate students of the University of Massachusetts at Amherst read 40 simple yes/no-questions on a computer screen. They were asked to indicate their answer to each question by pressing a designated key on the computer keyboard. We recorded each response and measured the response time. One subject was excluded due to an extremely long response time ( $>1 \mathrm{~min}$ ).

Each participant saw ten questions of each of the following types, the lists were counterbalanced, and no subject saw more than one type of question of each item.
a. Does a dog have tails?
b. Does a dog have two tails?
c. Does a goat have horns?
d. Does a goat have two horns?

We expected no responses for questions of type (33a) and (33b) and yes responses for questions of type (33c) and (33d). 
For all questions, subjects shared our intuitions more then $85 \%$ of the time. We will therefore call this response the "correct response". The graph on page 16 indicates though that there was a lower percentage of correct responses for questions of type (33a) (column 1) than for questions of type (33b) - (33c) (columns $2-4$ respectively). This is a significant difference as shown by the following tests: A one-way ANOVA between all conditions shows there to be a highly significant difference $(p<0.005)$. A second one-way ANOVA between the conditions corresponding to columns two, three and four does not indicate a significant difference $(p=0.09)$. A paired t-test between data reflected by columns one and two shows this difference to be significant $(p<0.05)$.

Four of our subjects consistently gave positive answers to questions of the type of (33a). When excluding these subjects from the data, we find the same pattern as described above, though due to the high variability in the data for responses to the questions of (33a) type, it is only a numerical trend.
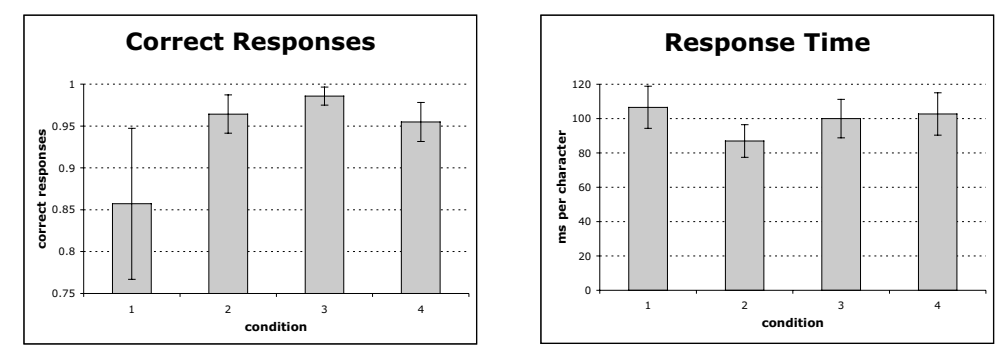

We excluded the four subjects that gave consistently positive answers for questions of type (33a) from our analysis of response time data.

To correct for length differences between our conditions we calculated response times in milliseconds per character (the items had an average length of 27.225 characters). We will report times in milliseconds per character below.

For questions with a negative answer and explicit numeral, as in (33b), the response time was on average $19.6 \mathrm{~ms}$ faster than for questions with a negative answer but without a numeral, as in (33a). By a paired t-test, the difference was found to be highly significant $(p<0.0005)$. For questions with an affirmative answer, the presence of a numeral was not found to have an effect on response times. Their average response time differed by $2.7 \mathrm{~ms}$, but this difference could not be shown to be significant (paired t-test, $p=$ $0.55)$. Finally, we found a significant interaction between the two conditions 
- absence or presence of a numeral and positive or negative answer $(2 \times 2$ ANOVA with subjects as random factor, $p<0.001$ ).

In these results, we found the difference between the bare plural and the explicit numeral in the case of questions expecting a negative answer. This difference corroborates the weak theory of the plural in combination with our assumption that the extra mental work involved with the bare plural should translate into greater reading times. For questions requiring the positive answer, however, we found no significant difference between the bare plural and the explicit numeral. This result is unexpected since comprehension of the bare plural in this case should also involve comparison.

While of course many interpretations of this result are possible, here is one suggestion how the result can be subsumed under the weak theory of the plural. The result shows that, contrary to our initial hypothesis, a comparison process per se does not lead to a significant increase in reading time. However, what we detected was an interference between the two sentences exactly in those cases in which they predict different truth values or responses. In the items expecting a negative response, the competing singular question would be answered 'yes', leading to a conflict. In the cases where we expect a positive response the singular questions would be answered 'yes' as well, but this time in agreement with the plural question. Therefore, no additional processing time is required in this case. This suggests that simultaneous computation of the truth values of two sentences that are to be compared is easily possible, but that if the two sentences actually lead to different responses, they interfere with each other and subjects require additional processing time to choose the correct response.

\section{Conclusion}

In this paper, we developed and argued for a weak theory of the plural. The weak theory, which we present in 1, is characterized by the assumption that the plural is not subject to an inherent lexical restriction as the singular is. Rather, the plural is subject to pragmatic comparison with the singular, and therefore cannot be used in most examples when the singular is possible. The evidence we used to argue for this result came from several different sources including experimental evidence, and therefore our study illustrates how different types of evidence can be used in generative linguistics.

One type of evidence we relied on were cases where adults could use the plural to refer to singularity. For reasons of space, we cannot consider in detail some phenomena that seem to suggest that sometimes the opposite 
is possible too: singular morphology with plural reference. One anonymous reviewer lists the following two phenomona in this category: the interrogative pronouns who and what and indefinite pronouns like man in German and on in French. ${ }^{8}$

(34) a. Who/What is arriving on the train?

b. Man kann da gut essen.

one can there well eat

'The food there is good.'

We propose that both examples in (34) involve reference to kinds. This has been proposed for what before: Based on data from the there-existential construction, Heim (1987) analyses what semantically as which kind of thing. We propose to extend this account by analyzing who as which kind of person and indefinite pronouns as referring to the most general kind of person. Though more details will need to be provided on this point, we show that data like (34) can, in principal, be accounted for under our proposal.

Our result has several interesting implications. First, compare our result with that of Greenberg (1966). Greenberg presents several tests for markedness that rely on morphology and on semantic interpretation. Based on these diagnostics, Greenberg claims that the singular is less marked than the plural, which is the exact opposite of our finding. Note that, though we did not consider Greenberg's account due to lack of space, all the arguments against the strong theory of the plural we presented equally apply to Greenberg's account. Actually, Greenberg (1966) presents only morphological data in support of his claim that the singular is unmarked. Hence, we propose that our result implies that semantic and morphological markedness need to be distinguished: The plural shows a mismatch between morphological and semantic markedness. Morphological and semantic markedness have not been distinguished as two different kinds of markedness before as far as we know.

A second interesting consequence of our result is that the interpretation of the plural always involves an implicit comparison. The related comparison processes with scalar implicatures have recently been an exciting area of psycholinguistic investigation (see the references in section 5). If we are right in claiming that similar comparison processes are involved in the interpretation of the plural, this opens up a new line of investigation for the study of comparison processes, which we regard as quite promising since the underlying semantic intuitions about number are usually sharp. The results in sections 5 and 6 are only preliminary steps in this direction. The results in section 5 correspond directly to data from scalar implicatures and therefore argues for the weak theory of the plural that we advoacate. The discussion in section 6 even 
provided one new insight concerning the general study of comparison processes: We concluded that the parallel computation of semantic values itself is not hard for the human processor, but that a comparison becomes difficult if the semantic values of two representations that are to be compared differ.

\section{Acknowledgement}

We are grateful to Pavel Nabutovsky for his help in conducting the acquisition experiment reported in section 5, and to Tom Roeper, Lyn Frazier, Irene Heim, Jonathan Bobaljik, Josef Bayer, Manfred Krifka, Daniel Taylor, the audience at the Linguistic Evidence Conference and two anonymous reviewers for their helpful suggestions. While writing this paper, Uli Sauerland was supported by an Emmy Noether Grant from the German Research Council DFG (Grant SA 925/1-1 and -2).

\section{Notes}

1 Varro's terms were actually loan-translations from Ancient Greek. Since Ancient Greek also has a dual form and the plural is therefore associated with cardinalities of three or greater, the term multitudinis is natural for the description of this language. Daniel Taylor (p.c.) points out that Aristotle credits Protagoras with the discovery of grammatical number.

2 Another class of relevant examples is exemplified by (i). For lack of space, we cannot address these here, but Sauerland (2003) offers an account.

(i) 1.0 children are missing.

3 Example (9c) is interesting to consider from the perspective of presupposition projection since the presupposition of the first disjunct at least is not globally satisfied. It is therefore similar to e.g. the example (i), which is frequently discussed, and we believe any solution to (i) would carry over to (9c).

(i) Either there is no bathroom in this house or the bathroom is in an odd place.

4 Unfortunately, we have not been able to investigate the empirical basis of Head's typological generalization in a systematic way. For Bengali, Josef Bayer (p.c.) has claimed that Head is empirically wrong. Furthermore, Head seems to include languages like Spanish on his list where not personal plural pronoun is used for polite address, but the special pronoun usted that has both a singular and a plural form. However, for several other languages Head considers we know his generalization to be empirically correct. 
5 Instead the singular form of the noun as in (i) must be used. One reviewer points out that, in the case of a surgeon addressing two people who both require an operation on their nose, both the plural (17) and the singular (i) can be used, though our account as stated predicts the plural to be obligatory.

(i) Ihre Nase muss operiert werden. pro.3PL nose-SG must-SG operated be.

Note that the second person singular can sometimes be used when the speaker addresses a group of people he is familiar with. For example, a teacher could say (ii) to his pupils. We assume that use of the singular form to address a group of people reflects a kind of distributivity at the speech act level such that each member of the addressee group is addressed individually.

(ii) Du musst höflich sein.

pro.2SG must-SG polite be

This phenomenon ought to be investigated further, but this is beyond the scope of this paper.

6 Here our account differs from the suggestion in Sauerland (2003) that indefinites project an existential presupposition, which is problematic because of (i) and similar examples.

(i) There aren't any unicorns.

7 Number marking on negative indefinites, however, is not always free; Jonathan Bobaljik (p.c.) provided us the contrast in (i). It seems that the singular must be used when it is established that the cardinality is either one or zero.

(i) a. No regulation prohibits this.

b. 'No regulations prohibit this.

8 The reviewer also mentions examples like (i) as possibly problematic for our account. We assume, though, that these contain a hidden variable that is bound distributively by the subject, such that (i) can be treated analogously to sentences like The soldiers each raise their right hand.

(i) Alle heben die rechte Hand.

All raise the right hand

\section{References}

\section{Bech, Gunnar}

1955/1957 Studien über das deutsche Verbum infinitum, volume 35 no. 2 and 26 no. 6 of Historisk-filologiske Meddelelser. Det Kongelige Danske Videnskaabernes Selskab, Copenhagen. 
Beck, Sigrid and Uli Sauerland

2000 Cumulativity is needed: A reply to Winter (2000). Natural Language Semantics, 8: 349-371.

Brown, Penelope and Stephen C. Levinson

1987 Politeness: Some Universals in Language Use. Cambridge University Press, Cambridge, UK.

Chierchia, Gennaro

1998 Plurality of mass nouns and the notion of "semantic parameter". In S. Rothstein, (ed.), Events and Grammar, pp. 53-103. Kluwer, Dordrecht, Netherlands.

de Villiers, Jill and Tom Roeper

1991 The emergence of bound variable structures. In Papers in the Acquisition of WH. GLSA, University of Massachusetts, Amherst.

Greenberg, Joseph

1966 Language Universals. Mouton, The Hague.

Gualmini, Andrea, Stephen Crain, Luisa Meroni, Gennaro Chierchia, and Maria Teresa Guasti

2001 At the semantics/pragmatics interface in child language. In Proceedings of SALT 11, pp. 231-247. CLC-Publications, Cornell University, Ithaca, N.Y.

Head, Brian

1978 Respect degrees in pronominal reference. In Joseph Greenberg, Charles Ferguson, and Edith Moravcsik, (eds.), Universals of $\mathrm{Hu}$ man Language, Volume 3, pp. 151-211. Stanford University Press, Stanford.

Heim, Irene

1987 Where does the definiteness restriction apply? Evidence from the definiteness of variables. In Eric Reuland and Alice ter Meulen, (eds.), The Representation of (In)definiteness, chapter 2, pp. 21-42. MIT Press, Cambridge, Mass.

1991 Artikel und Definitheit. In Arnim von Stechow and Dieter Wunderlich, (eds.), Semantik: Ein internationales Handbuch der zeitgenössischen Forschung, pp. 487-535. de Gruyter, Berlin.

Hoeksema, Jack

1983 Plurality and conjunction. In Alice ter Meulen, (ed.), Studies in Modeltheoretic Semantics, pp. 63-83. Foris, Dordrecht. 
Jacobs, Joachim

1980 Lexical decomposition in Montague-grammar. Theoretical Linguistics, 7: 121-136.

Krifka, Manfred

1989 Nominal reference, temporal constitution and quantification in event semantics. In R. Bartsch et al., (eds.), Semantics and Contextual Expressions, pp. 75-116. Foris.

Lasersohn, Peter

1995 Plurality, conjunction and events. Kluwer, Dordrecht, Netherlands.

Noveck, Ira

2001 When children are more logical than adults: Experimental investigations of scalar implicature. Cognition, 78: 165-188.

Papafragou, Anna and Julien Musolino

2003 Scalar implicatures: Experiments at the semantics-pragmatics interface. Cognition, 86: 253-282.

Penka, Doris

2002 Zur Semantik der negativen Indefinita im Deutschen. TübingenLinguistik-Report Nr. 1, Universität Tübingen.

Sauerland, Uli

2003 A new semantics for number. In The Proceedings of SALT 13, pp. 258-275. Cornell University, CLC-Publications, Ithaca, N.Y.

Schwarzschild, Roger

1996 Pluralities. Kluwer, Dordrecht, Netherlands.

Simon, Horst

2003 From pragmatics to grammar: tracing the development of 'respect' in the history of the German pronouns of address. In Irma Taavitsainen and Andreas H. Jucker, (eds.), Diachronic Perspectives on Address Term Systems, pp. 85-123. Benjamins, Amsterdam.

Taylor, Daniel J., (ed.)

1996 Marcus Terentius Varro: De Lingua Latina X. A new critical text and English translation, prolegomena and commentary. John Benjamins, Amsterdam.

van Eijck, Jan

1983 Discourse representation theory and plurality. In Alice ter Meulen, (ed.), Studies in Modeltheoretic Semantics, pp. 85-106. Foris, Dordrecht. 